América sin Nombre, n. ${ }^{\circ} 21$ (2016): 49-58

DOI: 10.14198/AMESN.2016.21.03

ISSN: 1577.3442 / eISSN: 1989-9831

Fecha de recepción: 03/06/2016

Fecha de aceptación: 13/10/2016
Puede citar este artículo como:

Cortijo Ocaña, Antonio. «Hacia una interpretación comprensiva de Sor Juana. Tres loas y la cifra del mundo». Teatro breve virreinal. Miguel Zugasti (coordinador). América sin Nombre, 21 (2016): 49-58, DOI: 10.14198/AMESN.2016.21.03

Link para este artículo: http://dx.doi.org/10.14198/AMESN.2016.21.03

\title{
Hacia una interpretación comprensiva de Sor Juana. Tres loas y la cifra del mundo
}

\author{
Towards a comprehensive interpretation of Sor Juana. Three loas and the cipher \\ of the world
}

\author{
Antonio Cortijo Ocaña* \\ University of California Santa Barbara
}

\section{Resumen}

Sor Juana Inés de la Cruz dedica gran parte de su obra al desciframiento del aparente laberinto de la realidad. Como intelectual, se imagina a sí misma como una segunda Proba, en sus funciones de intérprete, traductora y transmisora que, como Atanasio Kircher, ha de establecer correspondencias y similitudes. En Sor Juana América se convierte en tema de análisis y estudio, como puede apreciarse en particular en su Neptuno alegórico y en las loas a sus tres autos sacramentales: El divino Narciso, El cetro de José y El mártir del Sacramento.

Palabras clave: Sor Juana, Neptuno alegórico, América, loas, El divino Narciso, El cetro de José, El mártir del Sacramento.

\section{Abstract}

Sor Juana Inés de la Cruz devotes a great part of her work to deciphering the apparent labyrinth of reality. As an intellectual, she envisions herself as a second Proba, an interpreter, translator and transmitter who, just like Athanasius Kircher, must establish similitudes and correspondences. In Sor Juana America becomes a topic of study and analysis, as can be seen in her Neptuno alegórico and in the loas (preludes) to her three sacramental autos: El divino Narciso, El cetro de José and El mártir del Sacramento.

Keywords: Sor Juana, Neptuno alegórico, America, preludes, El divino Narciso, El cetro de José, El mártir del Sacramento.

Sor Juana afirma en su obra estar dotada de la suficiente legitimidad para hablar. El mulieres in ecclesia taceant paulino parece haberse clavado como una espina dolorosa en la mente de la jerónima, que protesta de variadas maneras contra una interpretación misógina de tal dictum. De ańadidura, interesa a Sor Juana hablar con insistencia de una serie de motivos recurrentes que aparecen en su obra entera. Estos motivos (posibilidad del conocimiento en el Primero sueño; reivindicación de la legitimidad cultural de lo

* Antonio Cortijo es catedrático de literatura española medieval y renacentista en la University of California Santa Barbara. Ha escrito 33 libros y ediciones sobre teoría de la historia en el siglo xvi (2000), novela sentimental (2001), Calderón de la Barca (2006), leyenda negra e ideología (2010), humanismo catalán (2011), Lope de Vega (2014), Sor Juana Inés de la Cruz (2015), Juan de Mena (2015), etc. Su ultimo libro se titula Mesianismo, epifanía y resurrección en el "Quijote”. La tolerancia de la contradicción (2016). 
novohispano en su Neptuno alegórico; exaltación de la figura mariana en sus villancicos; continuidad entre el Dios de las Semillas y la figura del Cristo crucificado en algunas de sus loas; afirmación de la capacidad intelectual femenina en la Carta atenagórica; etc.) no son independientes o autónomos, sino que están vinculados y relacionados entre sí, formando un haz unitario que explora lo que no es sino preocupación recurrente que se manifiesta de variadas maneras. Son, en definitiva, manifestaciones de un único tema que ocupa la obra entera de la jerónima: la posibilidad de conocer o descifrar el problema del mundo a través del establecimiento de relaciones, similitudes, semejanzas, alegorías. Dentro de esta temática, Sor Juana ofrece apreciaciones originales sobre el concepto de América en algunas de las loas a sus autos sacramentales. Estas apreciaciones (basadas en el procedimiento cristiano tipológico-alegórico de la superación de las edades hasta llegar al advemiento de la Ley de Gracia) han sido generalmente interpretadas por la crítica en relación a lo que se ha denominado como criollismo incipiente. Pero también se ha alzado alguna voz con un enfoque complementario atendiendo a la teología; como defiende Zugasti

es una loa [la de El divino Narciso] con un argumento muy bien definido, donde las alegorías no son estereotipos, sino que actúan, reflexionan y varían sus puntos de vista. Sor Juana plantea un problema teológico de gran calado, como es presentarnos al nuevo continente en su estado prehispánico, todavía en la fase de la Ley Natural. De ahí el arranque musical con cantos y danzas aborígenes (tocotín), así como la explicación de su religiosidad: son idólatras y practican sacrificios humanos; en este contexto, la loa se centra en una tradición nahua que celebra, en honor del «dios de las semillas» (Huitzilopochtli), la ceremonia del teocaulo, o sea, el dios es comido por los indios en rito purificador. Inmersos en este estado natural están Occidente y América hasta su encuentro con Religión y Celo, que ya viven en la era de la Ley de Gracia e intentan convertirlos a la fe católica. Este encuentro es un apretado resumen del proceso de conquista y colonización (133).

Aquí me interesa insertar estas loas en un contexto que las imbrique con el resto de la producción sorjuanina, desde donde alcanzan un significado más completo. En varias ocasiones he recalcado el papel de Sor Juana Inés de la Cruz como intérprete, asemejándolo al desempeñado por una figura como la de la centonista Falconia Betitia Proba (ca. 306/315
- ca. 353/366), muy querida a la monja jerónima, que se había encargado nada menos que de cristianizar la Eneida virgiliana en el siglo Iv (Fassina, Green) ${ }^{1}$. Como en el caso de las reinterpretaciones de la Égloga IV de Virgilio, que se leía en clave cristiana como anunciadora del nacimiento de Cristo en lugar de su significado originario como heraldo del nacimiento del futuro emperador, Proba lee la épica virgiliana como una continuidad entre el mensaje clásico y el cristiano, indicando así que no hay solución de continuidad entre ambos y que existe entre ellos una línea de unión en su sentido más que una cesura o un corte cultural abrupto, basada en unas correspondencias ocultas que ella se encarga de dilucidar. En el clima del siglo iv, con la religión nueva convertida en caballo de batalla entre novatores y tradicionalistas, entre quienes ven en ella algo ajeno al imaginario romano y quienes la señalan como anclada en esencia en el mismo, el esfuerzo de quienes buscan motivos de contacto más que de separación tajante entre sistemas bucea en nociones como las de hibridez o permeabilidad (Schapp). Como Proba, Sor Juana se imagina a sí misma a modo de bisagra o puente que une los mundos de referencia de la tradición cultural europea y la americana. En su intento por navegar a dos aguas, su programa se centrará a lo largo de gran parte de su obra por descifrar una realidad oculta y buscar similitudes que ayuden a explicar la cifra del significado latente: unir, por ende, más que distinguir.

El Neptuno alegórico es la obra donde mejor queda expuesta esta perspectiva (ed. Martin). El nuevo virrey, Tomás Antonio de la Cerda, que acude a su puesto para hacerse cargo de las riendas del poder en 1680, es recibido como merece su categoría con ceremonias de bienvenida y arcos triunfales en la Nueva Espańa. El cabildo catedralicio de la Ciudad de México encarga a Sor Juana que redacte un poema celebratorio y encomiástico, como piden las circunstancias, para la recepción de la nueva personalidad por parte de la ciudad. Sor Juana se prepara a conciencia. Rastrea por entre los apellidos del vicemonarca (Laguna, Paredes) y los manuales al uso de mitografía (Conti, Vitoria, etc.). El resultado es

1. La idea del presente artículo parte de una sección del capítulo «Hacia una interpretación comprensiva: Primero Sueño, autos y loas", de mi monografía Sor Juana Inés de la Cruz o la búsqueda de identidad (Sevilla, Renacimiento, 2015), de donde proceden, modificadas y recontextualizadas, alguna de mis apreciaciones. 
una pieza compleja que se construye mediante un abigarrado haz de referencias a motivos y temas sacados del mundo clásico, de preferencia mitológicos. El marqués de la Laguna, uno de sus títulos nobiliarios, es un segundo Neptuno que, con su esposa Anfitrite, ha cruzado el mar para hacerse cargo del gobierno americano. Con la referencia a Neptuno y Atenea/Isis, Sor Juana hace que las dos figuras se den la mano para representar la conjunción de fuerza y sabiduría que habrá de guiar su labor de rección del Imperio en América (Arenal, Bouvier, Català, Grossi, Olivares Zorrilla). Como el Neptuno mitológico, deidad fundacional de la Ilias troyana, el nuevo virrey porta con su cetro la llama civilizadora que se traspasa del mundo europeo al americano en una especie de translatio imperii. Eneas, superviviente de la conflagración troyana, escapó de la ciudad en llamas portando consigo a sus dioses penates, a su hijo Ascanio y a su padre Anquises. Con ellos se embarca en un viaje fundacional que acabará, como relata Virgilio en su Eneida, con el establecimiento de la Urbs por excelencia, Roma, marcando de paso la ilación cultural e ideológica (una especie de viaje ininterrumpido a lo largo del tiempo) entre los mundos culturales griego y romano.

¿Qué quiere resaltar Sor Juana al encomiar al virrey como deidad fundacional del traspaso? Pensamos que es en especial su simbolismo como transmisor y mediador, en su función de representante de sus nuevos súbditos americanos, que no son sino continuación en la contigüidad del espacio de los valores representados por la España peninsular. La figura de Eneas también reivindicaba el papel de transmisión o continuación cultural que Roma representaba en el imaginario octaviano y virgiliano con respecto a Grecia. Con ello se legitimizaba el papel cultural de un imperio romano que partía en situación de franca inferioridad con respecto a las consecuciones culturales del mundo griego. No rivalizamos con ellos (los griegos), parece decir Virgilio, sino somos ellos mismos proyectados hacia el futuro en una misma línea de continuidad, aderezada con los aditamentos de nuevos tiempos y nuevas culturas con las que hemos entrado en contacto. Del mismo modo, Sor Juana legitima al sujeto americano como miembro de una comunidad cultural proyectada en el espacio y el tiempo insistiendo en algunas notas que hacen de dicho sujeto elemento novedoso.

Sor Juana recurre para su método comparativo cultural al utilizado por el filósofo y polígrafo Atanasio Kircher, conocido en la época por sus escritos sobre mitología y en especial como interpretador del mundo de los jeroglíficos egipcios: Prodomus Coptus Aegyptiacus, Obeliscus Pamphilius, Oedipys Aegyptiacus (Rivosecchi, Reilly). Al hacer esto le interesa a Kircher practicar lo que puede denominarse como religión comparada o estudios de religión cifrada. Convencido de la univocidad del mensaje religioso y su multiplicidad de manifestación en los variados ropajes de las distintas religiones, Kircher se apresta de modo pionero a desentrañar el significado oculto de la cifra que se oculta ya sea en las relaciones entre el Viejo y el Nuevo Testamento, ya sea en los jeroglíficos egipcios, en persecución de lo que él imagina como un arquetipo religioso y hasta político $^{2}$. En otra ocasión resaltábamos que

ser intérprete no conlleva un significado pasivo de simple transmisor, sino se constituye en un papel activo como reinterpretadora. Para ello Sor Juana se sirve de un autor como Atanasio Kircher. Éste había dedicado su tarea intelectual a la labor de mitógrafo. Pero lejos de seguir en la órbita de Conti o Valeriano, prefiere imaginarse como (re)constructor de símbolos y arquetipos. Para ello, desde su manejo de lenguas y su educación en sistemas de pensamiento diversos busca establecer relaciones simbólico-alegóricas de la realidad, que él concibe como unitaria aunque multiforme. La base enciclopédica del saber de Vitoria se le queda pequeña, pues Kircher descubre en Egipto un arcano de saber que penetra en la realidad escondida y subyacente a las cosas. Esta búsqueda del arquetipo que Kircher se esfuerza en perseguir es la que suele primar en momentos que se pueden caracterizar como de crisis, momentos que se sitúan a caballo entre épocas, entre sistemas de pensamiento divergentes, entre posturas heterogéneas de ver la realidad o desde regiones consideradas periféricas o marginales con respecto a un centro de poder (judaísmo/islamismo/ cristianismo; época precolombina/época colonial). Es en estos momentos cuando surge una necesidad de simbiosis, de mixtura, de correlación, que permita avanzar de un momento a otro y de un sistema a otro sin establecer una ruptura total. Es en este momento cuando el (re)intérprete alcanza un puesto de privilegio, porque permite realizar dicha transición. Es en este papel como Sor Juana se define en parte a sí misma dentro de su contexto novohispano, del mismo modo que Proba había querido ver una relación entre el cristianismo y Virgilio, de la misma manera que los

2. Remito a sus Principis Christiani archetypon politicum. 
padres de la Iglesia habían querido ver en el Antiguo Testamento una prefiguración del Nuevo. Es un lanzar puentes y establecer nexos más que manifestar el deseo de ruptura y disyunción. (Cortijo, 2015, 352)

En esta labor sincrética pueden verse notas de heterodoxia. Entendemos por ello el ejercicio de un modus operandi que se sale fuera de la norma, de lo establecido. El contacto de Kircher con un mundo enteramente desconocido (el egipcio) y que no se amoldaba a los patrones de interpretación que el estudioso había adquirido en su preparación clásica (grecorromana) y semítica (estudio de las lenguas hebrea y caldea), obligaron al jesuita (salvo que hubiera querido considerar como falsa la verdad cristiana) a indagar por un método comparativo de analogías y semejanzas. Sospechamos que Sor Juana llega a la misma conclusión por su acceso anómalo a la cultura, desde el margen, amén de por su carácter americano que la obliga a entrar en contacto con una realidad indígena (y precolombina) de cuyo Dios de las Semillas debe dar cuenta como predecesor americano. Un margen representado en primer lugar por su condición de mujer que no ha accedido al saber desde el cursus honorum prototípico del momento (el universitario y masculino), a través de las academias de estudio y los libros prescritos en la época. Al contrario, su condición de autodidacta le ha permitido espigar textos diversos de diferentes fuentes, coincidiendo a la postre con los gustos anómalos de alguien como Kircher, cuya erudición e inquietudes intelectuales le hacen salirse del camino trillado y espigar en textos que se escapan de lo común, del acervo aceptado por una tradición escolar establecida. En segundo lugar, su posición marginal debe asociarse en parte a su condición colonial, aunque se le dé a este término un cariz menos reivindicativo de lo que generalmente se acepta (Moraña, Martínez-San Miguel). Desde la colonia, desde el margen (territorial y cultural del Imperio español), la monja se ve ante la tesitura de explicar una realidad que incorpora elementos culturales españoles e indígenas extraños y el método sincrético de Kircher le permite un modo de incorporarlos dentro de un imaginario común.

Pero Kircher y su método de interpretación de la cifra representan sólo uno de los elementos inspiradores de Sor Juana. Un segundo elemento inspirador radica en el aparato ideológico cristiano que subyace a los autos sacramentales de autores como Calderón de la Barca: el tipológico-alegórico (Cortijo, 2006). En estas obras Calderón usa un esquema intelectual preestablecido sobre el que insiste con asiduidad. La religión nueva, el cristianismo, la Nueva Alianza, supone una Ley de Gracia que supera la Vieja Alianza representada por el Antiguo Testamento, del modo como la última suponía la superación de la Ley Natural. Este viaje de manifestación de Dios en el mundo y en su pueblo queda representado para Calderón y los autores de este género mediante las figuras de la Gentilidad, el Judaísmo y el Cristianismo, o mediante las de la Ley Natural, la Ley Escrita y la Ley de Gracia. Es un viaje que supone un continuum en que se avanza por mor del aditamento y la mejora más que por la ruptura tajante y el comienzo de nuevo. La novedad se expresa en términos metafóricos a través del concepto de conversión que simboliza san Pablo, el hombre nuevo renacido que se despoja de su ser anterior sin dejar de ser él mismo en virtud de un nuevo modo (caritativo) de entender su humanidad. Y en último término, el referente de su conversión tiene como modelo el renacimiento del Dios de Amor a quien presta su fe, que por el acto de su vencimiento de la muerte señala precisamente su papel de continuador.

Sobre estas dos tradiciones sincréticas, la de la alegoría cristiana y la de la pirámide kircheriana que representa el movimiento dialéctico y de síntesis de interpretación de la realidad, se mueve Sor Juana, émula de Proba. En el Primero sueño, obra que ha sido catalogada por la crítica como opus maximum de la monja jerónima, el alma, en su acto de conocer,

semeja realizar un vuelo hacia arriba, parecido al que representa el símbolo-emblema de las pirámides (el alma es pirámide mental, aquéllas son «bárbaros jeroglíficos de ciego error»), signos externos de las dimensiones interiores que son especies intencionales del alma: el alma sube hacia arriba como el fuego, aspirando al Centro, Causa Primera, «al que tienden todas las líneas rectas (toda verdad y justo anhelo), y la Circunferencia infinita que en sí contiene -virtual y eminentemente- todas las esencias» (Méndez Plancarte 609) y en busca del «vuelo intelectual con que ya mide / la cuantidad inmensa de la Esfera ${ }^{3}$ :

3. Olivares Zorrilla indica que «el Primero sueño, como sueño de anábasis, nos señala por igual esa cumbre intelectual a la que se dirigen místicos y contemplativos, aunque ese señalamiento sea onírico, una refracción en el espejo del Faro o la fantasía, un poco más abajo. Las proyecciones descritas en el poema, por lo mismo, no son azarosas o erráticas como en cualquier sueño, sino intencionales, pues son una refracción de la luz del intelecto agente. Sueño enigmático u oneiros, el Primero sueño es, pues, un sueño verdadero visto por la 
Las Pirámides fueron materiales

tipos solos, señales exteriores

de las que, dimensiones interiores,

especies son del alma intencionales:

que como sube en piramidal punta

al cielo la ambiciosa llama ardiente,

así la humana mente

su figura trasunta

y a la Causa Primera siempre aspira

-céntrico punto donde recta tira

la línea, si ya no circunferencia,

que contiene, infinita, toda esencia-. (Cortijo,

2015, 390)

Desde la altura que supone el punto máximo del vértice superior de la pirámide, el alma quiere avizorar la realidad para comprehenderla en su totalidad. Pero parece condenada al fracaso de esta primera vía intuitiva, pues sólo acierta a vislumbrar «bárbaros jeroglíficos de ciego error» cuyo significado se le escapa. El proceso intelectual se imagina labor de desciframiento, de modo semejante a como Kircher se había tenido que enfrentar a los jeroglíficos indescifrables egipcios, o como la misma Sor Juana debe vérselas ante dos realidades y mundos culturales en apariencia desemejantes: el español y el indígena.

Esta labor de desciframiento del enigma o de interpretación de la cifra del mundo no deja de estar presente en gran parte de la literatura barroca del momento. Subyacen a ello los conceptos del misterio del laberinto del mundo, del ocultamiento y la desilusión, que provocan actitudes un tanto desengañadas ante una realidad que se muestra velada, misteriosa, oculta, de difícil comprensión. En Sor Juana, no obstante, creemos percibir que la importancia de este tema desborda con creces el espacio de un topos de época. Es más, permea su producción en conjunto, que puede leerse como si se tratara de una insistencia reiterada sobre dicha problemática, como hemos defendido en nuestra monografía sobre la monja. Sor Juana busca en sus escritos situarse a sí y al espacio (americano) que ella ocupa dentro de la cifra del mundo, es decir, legitimarse como mujer humanista (intelectual) y a lo americano como sujeto cognoscitivo. Dicha cifra sólo alcanza sentido para ella si se

puerta córnea o translúcida de la que hablan los autores de la Antigüedad. [...] En Pia desideria, del jesuita Hermann Hugo, encontramos un Faro -Dios en la noche de la existencia- que conduce al alma enamorada de la Divinidad por los meandros de la vida, como Ariadna a Teseo» (83-84). ve como un proceso dialéctico de manifestación de la historia que avanza de Isis a Osiris a Horus (como insiste Atanasio Kircher), como manifestación de la operación de la inteligencia (asexuada) aplicada al universo de las realidades cognoscibles, como prolongación del Dios de la Semilla indígena en el Dios Cristiano, trasuntos todos de un mismo enigma.

Las Loas que preludian tres de los autos sacramentales de Sor Juana (El divino Narciso, El cetro de José y El mártir del Sacramento) reflejan esta problemática de varias maneras, centrándose de preferencia en el problema de América como concepto. En la Loa para El divino Narciso se reproduce en las tablas una especie de requerimiento. Occidente y América aparecen en el escenario a punto de celebrar un sacrificio (cruento) a su Dios de las Semillas (BénassyBerling, Jáuregui, Zanelli, Zugasti 132-135). Celo quiere vengarse por lo que considera afrenta malvada y osadía del paganismo. Religión desea convencerles para que abandonen el culto profano, pues reconoce que sólo en el conocimiento puede basarse la verdadera conversión («no hay fuerza ni violencia / que a la voluntad impida / sus libres operaciones», ed. Rivers, 814 , vv. 240-242) ${ }^{4}$. Pero lo que es más importante, en su labor de disuasión se percata de que la verdad subyacente a ambas religiones es una y la misma, bajo capa de diferentes cifras. Así, se dirige a América y Occidente en los siguientes términos:

¡Válgame Dios! ¿Qué dibujos, qué remedos o qué cifras

de nuestras sacras verdades quieren ser estas mentiras? (814-815, vv. 201-204)

Les refiere al ejemplo de san Pablo (cuando éste predica a los atenienses diciéndoles que 'No hay deidad nueva') y les dice con respecto a su Dios de las Semillas y sus cultos:

Esos milagros que cuentas, esos prodigios que intimas, esos visos, esos rasgos que debajo de cortinas supersticiosas asoman; esos portentos que vicias, atribuyendo su efecto a tus deidades mentidas,

4. Las citas de la obra de Sor Juana proceden del volumen Poesía, teatro, pensamiento. Lírica personal. Lírica coral. Teatro. Prosa (2004), editado por Georgina Sabat de Rivers y Elias Rivers. 
obras del Dios verdadero,

y de su sabiduría

son efectos. (816, vv. 297-307)

Si la Loa es preludio al auto, no hay tampoco una distancia insalvable entre el Primero sueño y El divino Narciso. El protagonista, Narciso, se lamenta en el mismo (el dolor de que muere no gozando lo que quiere, la ninfa hermosa caída en pecado) dejándonos saber que su alma muere de tristeza «buscando mi semejanza» (891), idea que se erige en trasunto del auto entero, que se asemeja así al ascenso del alma en el Primero sueño (en su sed de conocimiento) en camino a la unión (hipostática) visionaria con su Dios. La búsqueda de la semejanza implica asimismo la realidad de la ocultación aparente que hace difícil su resolución. Por todo el auto (y su Loa) abundan imágenes que refieren a la ocultación, el escondimiento, el (re)descubrimiento, todo ello dentro de un esquema tipológico en que se presenta la evolución de la Ley Natural a la Escrita y la de Gracia. La composición entera, basada en el procedimiento de la alegoría, construcción que pasa en juego de espejos de una imagen a sus reflejos, se tematiza en el contenido mismo del auto: la muerte de Dios por su trasunto, el alma:

Hallo que todo mi estudio

sirvió de ponerle medios

para que su amante orgullo

la mayor fineza obrase,

muriendo por su trasunto. (900, vv. 1691-1695)

Pero puede ahondarse aún más. Podría incluso postularse que el ansia de conocimiento, que resultaba frustrada en el Primero sueño, alcanza satisfacción en el auto mediante el uso del verbo conocer en el sentido de reconocer, basado a su vez en la idea de la semejanza entre el Amado y la Amada, metáfora de honda raigambre en la poesía amorosa y mística ("Amada en el Amado transformada», como diría San Juan de la Cruz en su Noche oscura). Narciso, «archivo de perfección» y "gozando felicidades en la gloria de sí mismo», se siente atraído como imán hacia sí mismo (apuntando a la identidad o mismidad de los mensajes que subyacen a las varias religiones). Así, tanto el Alma que se debate por conocer la realidad última en el Primero sueño como Narciso que se autoinmola son, pues, semejanzas y trasuntos de una historia cifrada.

En otras ocasiones la cifra en que se oculta la realidad se manifiesta como los dos términos aparentemente disímiles de un debate dialéctico. En la Loa de El mártir del Sacramento, san Hermenegildo, dos estudiantes deliberan cuál es la fineza mayor de Cristo (Farré Vidal): dar lo necesario o lo sobrado (morir o quedarse en el Sacramento eucarístico). Ante la dificultad de razonar sobre el tema con palabras, los estudiantes hacen visibles los objetos al entendimiento con alegóricos entes, creando así «un auto del divino sacramento alegórico-historial». El Estudiante 3 es el encargado de actuar de juez de la disputa entre los otros dos, lo que se describe como un «mediar / vuestra cólera» (923), remitiendo a la función de intérprete o mediador que la misma Sor Juana ha aprendido de sus modelos intelectuales, Proba o Kircher. Los contendientes tratarán sobre el significado y precedencia cronológica de la Cena y Lavado de pies. Si el lavatorio ocurrió previo a la Cena, dice el Estudiante 3, ello hace al «intento místico» porque «fue figura del Sacramento», es decir, de la Penitencia, «para enseńarnos que no / tengamos atrevimiento / de llegarnos al altar / sin lavar antes los yerros» (938). De nuevo estamos ante lo que no es sino un problema intelectual, el de la solución de un enigma encerrado u ocultado bajo una velada semejanza. En la Loa aparecen, de modo un tanto enigmático, las figuras de Hércules y Colón. El primero representa con sus trabajos y conquistas el establecimiento del famoso Non Plus Ultra; el segundo la superación del mismo con su descubrimiento de América:

\author{
No haber más mundo creía \\ Hércules en su blasón, \\ mas se echó al agua Colón \\ y vio que más mundo había. \\ Así cuando se entendía \\ que el llegar a padecer \\ era el sumo poder \\ la empresa mayor que vieron, \\ se echó al agua, y conocieron \\ que quedaba más que hacer. (936-937, vv. 367-376)
}

Son figuras de los momentos representados por el Lavatorio y la Cena, entre los que cabe una relación de contigüidad pero a la vez de superación dialéctica. Como en el caso del Neptuno alegórico, o hasta los de Occidente y América en la loa anterior, Sor Juana no puede permanecer por mucho tiempo ajena a la realidad americana. Colón prorrumpe diciendo que «Más mundos hay, más imperios», y con ello subsume el sentir de Sor Juana ante el virrey marqués de la Laguna: la tierra americana supone el lugar donde opera la translatio, donde Sor Juana vislumbra una 
transferencia continuada; a desentrañar su sentido parece abocada la inteligencia en su afán por descifrar el sentido del mundo.

En la loa de El cetro de José y en el auto de este nombre, el procedimiento de la figuración tipológica y/o alegórica queda personificado en la obra misma, haciendo tema del procedimiento utilizado. El auto aborda los límites del conocimiento de Inteligencia (aliada de Lucero/Lucifer en la obra) y de Conjetura, su ayudante; si el objeto al que se aplica la misma recibe la gracia, según afirma el personaje Providencia, «donde la luz / se aparece, no han tenido / las tinieblas permanencia» (1117, vv. 1600-1602). La Loa nos muestra a la Ley Natural y la de Gracia congratulándose en escena por la conversión «de las Indias conquistadas", que no son sino "el complemento" que la Ley de Gracia había deseado por largo tiempo. Con ello se anuncia el tema de la (pre)figuración que será materia del auto propiamente dicho. Fe, Ley de Gracia y Naturaleza piden en un momento determinado a las «sutiles inteligencias», las «espirituales substancias», las "esencias incircunscriptas» $\mathrm{y}$ las «entidades soberanas» de las tres jerarquías y los nueve coros que bajen del Empíreo a ayudar en la labor de conversión de la Idolatría. Como ocurría en la loa de El divino Narciso, estos varios personajes se aprestan a mostrar a Idolatría lo cercana que está de la salvación cristiana, pues los sacrificios (humanos) no son sino prefiguración del sacrificio cristiano, el más delicioso imaginable:

Pues yo pondré en las aras

un holocausto tan puro,

una víctima tan rara,

una ofrenda tan suprema,

que no solamente humana,

mas también divina sea. (1045, vv. 394-399)

Desde el momento que el hombre hace su aparición en la tierra cae en pecado. A partir de aquí se redime 'subsecuentemente'. Las diferentes edades históricas, según dice Sor Juana en el auto, ofrecen ejemplos de figuras que son misterios o enigmas de dicha redención, a poco que el hombre aplique su Inteligencia para saberlos desentrańar, siempre moderada por la Profecía (divina). El procedimiento se describe con exactitud en los versos iniciales del auto. Dios concede al hombre varias apelaciones que van trascendiendo de siglo en siglo; al hombre debe aplicar su inteligencia, junto a su fantasía e imaginación, para inferir su significado. La misma inteligencia humana, que le condenó al pecado al transgredir el mandato divino, ahora, bien aplicada, es capaz de liberarle de su condena: «Discúrralo, si puedes, tu conciencia, / pues es punto que toca a Inteligencia» (1057, vv. 182-183).

Cuando al fin del auto se produce la reconciliación entre José y sus doce hermanos, Sor Juana se demora en la explicación de la equivalencia entre el alimento de la cena egipcia y el del pan/Pan de salvación/vida de Cristo. La dificultad del misterio se anota de nuevo en términos cognoscitivos, que sólo producen asombro y confusión, tinieblas crueles que «ofuscan la perspicaz luz de mi angélica mente»:

Y ¿quién duda que es así,

pues Dios, como y cuando quiere,

me turba el conocimiento

o el discurso me entorpece? (1102, vv. 1239-1242)

El auto concluye con la conversión de la vara de Jacob en portadora del pan eucarístico, maná rehecho, figura de un Cristo

no sólo a mi carne unido

con hipostática unión,

mas en el velo escondido

de esa insignia que, en tu cetro,

de tu providencia indicio

ha sido. (1115, vv. 1552-1557)

La vara coronada con «una torta de pan en la punta» es un «jeroglífico esculpido» que declara las hazañas del héroe Jesús. El viaje de búsqueda especulativo, que parecía condenado a un fracaso relativo en el Primero sueño, llega ahora a su cenit o esplendor máximo con la ayuda divina en el auto de Sor Juana. Por ello, y una vez más expresado con terminología mistérica y ocultista, Profecía prorrumpe al final del mismo en un epinicio que significa una celebración de la Luz sobre las Tinieblas, la inteligencia sobre la ignorancia, casi punto por punto del modo opuesto (o si se quiere la solución complementaria) a como culmina el viaje nocturno de la mente en el Primero sueño:

¡Idos, que donde la luz se aparece, no han tenido

las tinieblas permanencia! (1117, vv. 1600-1602)

Las tres Loas analizadas guardan una imbricación especial entre sí desde un punto de vista del contenido. En ellas, igualmente, se presta particular 
atención al concepto de América y al de la Inteligencia que es capaz de desentrañar el significado oculto por medio de figuraciones de lo enigmático. La loa de El mártir del Sacramento, san Hermenegildo proclama que hay una continuación histórica entre Alcides y Colón, como la hay entre la monarquía hispánica europea y la americana, o como se produce en la superación de la Ley Natural por la de Gracia. Sor Juana hace, así, uno de los dos temas de la relación tipológica entre Antiguo y Nuevo testamentos y la legitimación cultural americana o colonial por mor de haberse operado una translatio imperii en suelo americano. En el Antiguo Testamento se cifra el Nuevo; América es el desciframiento del devenir histórico de un pueblo y una cultura, iniciados en la Península Ibérica. La tipología bíblica y la especulación política (que era inherente al Neptuno alegórico) no están desvinculados, sino atados por una especie de destino político-cultural. Idolatría lo expresa con rotundidad en la loa a El cetro de José, dirigiéndose a la Fe:

Soy, por más que tú me ultrajas,
la que sabrá defender
fueros de edades tan largas,
pues alegórica idea,
consideración abstracta
soy, que colectivamente
casi todo el reino abraza. (1040, vv. 264-270)

Se proclama plenipotenciaria de los indios, «que a un solo Dios adoran». Su yerro, avanza, no estaba en el sacrificio, sino en el objeto. La Fe se apresta a mostrarle "un auto sacramental / y alegórico» en que su amor hará visibles las profecías que hablan de un gran misterio "de pan y trigo", semejanza del tributo sacrificado del maíz. La misma idea se repite machaconamente en la loa de El divino Narciso. En ella Celo y Religión discuten para oponer respectivamente la fuerza de la conversión a la convicción:

... porque vencerla por fuerza

te tocó; mas el rendirla

con razón, me toca a mí,

con suavidad persuasiva. (812-813, vv. 214-217)

Esta rendición por persuasión nos permite dar un paso más y vincular las loas y el Neptuno alegórico al Primero sueño, donde la Inteligencia asciende por la pirámide del sueño en busca de su semejanza. La aventura de Isis (Inteligencia) no es diferente de la de Neptuno (Celo), que busca extender su dominio entre iguales (semejantes) haciéndoles partícipes de los arcanos de la sabiduría. Dominio y Prudencia eran los dos atributos del mando y la rección política de naciones que más se elogiaban en el Neptuno alegórico y en el virrey. Dominio y Prudencia/Inteligencia son los calificativos que aúnan a Celo y Religión en las tres loas comentadas. A la figura de la Religión persuasiva se añaden las de Alcides/Hércules y Colón. Se trata en esencia de bucear entre un imaginario gnoseológico y político que en último término es trasunto del afán de dominio de la realidad por captación de su sentido último. Este sentido final, significado último de las cosas, permanece cerrado y hermético, cifrado, velado. Este solapamiento e ininteligibilidad aparentes semejan los jeroglíficos que Kircher se afanara por interpretar. Son un lenguaje cifrado que sólo espera la clave que posibilite su intelección.

Sor Juana se lanza en su obra tomada en todo su conjunto a una aventura intelectual de desciframiento. Conquista (territorial, intelectual, espiritual) es para ella apertura, pasando de la contigüidad en el espacio y el tiempo a un descubrimiento de sentido. Las loas son preludio de sus autos y son canto de alabanza del misterio eucarístico. Son, por extensión, superación del Non Plus Ultra representado por Alcides/Hércules de la Loa de El divino Narciso con que se cerraba toda posibilidad de intelección y de expansión. Como es frecuente en los grandes escritores, los temas, modos y motivos de la obra sorjuanina se muestran recurrentes, dando así idea de la concepción global de la misma por parte de la jerónima, reflejo de sus preocupaciones por el misterio enigmático de la comprensión inteligente del universo.

Proba hizo mucho más que traducir la Eneida en clave cristiana. Conocedora y enamorada de la obra de Virgilio, que era para ella modelo de literatura latina y del ethos romano, sostén y portaestandarte de una tradición cultural, se le hacía imposible que sus valores y contenido estuvieran en disonancia con los del mundo cristiano al que se había convertido. Su afán fue el de encontrar semejanzas, continuaciones, contigüidades, puntos de contacto que revelaran entre los mundos pagano y cristiano una línea de transmisión más que de ruptura. Suponían, en suma, un modo de ver el mundo. No muy alejado de dicha metodología (la de la concomitancia) se muestra Atanasio Kircher, para quien el mundo entero es una cifra que esconde identidades expresadas en lenguajes disímiles. Todo su afán como estudioso consiste en enfocarse no en las líneas de la pirámide que ascienden sin encontrarse en su base, sino en el punto del 
vértice superior en el que por fin se encuentran y reúnen. A la Trinidad cristiana se superpone la tríada Isis-Osiris-Horus, manifestación trina de una realidad que avanza de manera dialéctica hacia su superación en una síntesis mayor que el producto de sus partes. Sor Juana, que opera como Proba y Kircher, vive en una realidad barroca y americana. Dentro de ella, amén de en cuanto a su condición de mujer (intelectual americana autodidacta), se plantea su labor como la de una transmisora que asegura que no se interrumpa el movimiento del saber heredado de la tradición. Así lo plantea en la casi totalidad de su obra, que se construye alrededor de una serie de temas recurrentes que giran en torno a la posibilidad de conocimiento. Así se lo dice el marqués de la Laguna (instándole a que entienda su dominium de la misma manera), pidiéndole que vea en sus súbditos sujetos legitimados a los que transmitir (como Eneas) los dioses penates del solar ibérico. Así se lo dice a los espectadores de sus autos y loas, a quienes insta a ver en el mundo precolombino una prefiguración (válida) hispánica y por ende a su semejante. Así lo reclama de su propia Inteligencia, a quien en el Primero sueño pide que ascienda como en pirámide hacia la comprensión de su semejanza, de sí misma («a la mental pirámide elevada / donde, sin saber cómo, colocada / el Alma se miró» (447, vv. 424-426):

\section{Las Pirámides fueron materiales}

tipos sólo, señales exteriores

de las que, dimensiones interiores,

especies son del alma intencionales,

que como sube en piramidal punta

al cielo la ambiciosa llama ardiente,

así la humana mente

su figura trasunta

y a la Causa Primera siempre aspira,

céntrico punto donde recta tira

la línea, si ya no circunferencia,

que contiene, infinita, toda esencia. (447, vv. 400-411)

Las «tinieblas de ignorancia» hacen que las perfecciones de la Ley Natural queden como «apagadas» (Loa para El cetro de José, 1030, vv. 18 y 20) y sólo la Ley de Gracia pueda esmaltar los preceptos y perfeccionar el ser de dicha Ley Natural. Se trata, en esencia, de conjuntar a Neptuno e Isis (su madre), elementos masculino y femenino (superados en un concepto de la inteligencia asexuado, por así decir) que representan en último término el consejo, la sabiduría, el conocimiento, la capacidad racional: ímpetu y reflexión. Pero las tinieblas de ignorancia no implican una imposibilidad de conocer, sino la afirmación de la apariencia cifrada de la realidad y la ocultación aparente del objeto de conocimiento. Kircher fue el primero que introdujo en su reflexión sobre el mensaje cristiano todo el mundo egipcio de referencia para relacionarlo con el esquema de la tradición judeocristiana. Sor Juana es quien primero introduce América como concepto (problema, enigma) en dicha tradición, problematizándolo en particular en las loas a sus autos El divino Narciso, El cetro de José y El mártir del Sacramento, y dando de resultas a lo americano una legitimidad como sujeto y objeto de conocimiento. Y lo hace desde un ejercicio de inteligencia que bucea por entre las tinieblas para encontrar formas transferibles, esencias traducibles que posibiliten la continuidad de la transmisión cultural (no somos sino enanos aupados a hombros de gigantes, como quería Bernardo de Chartres) más que coartarla.

\section{Bibliografía}

Arenal, Electa. «Enigmas emblemáticos: el Neptuno alegórico de Sor Juana Inés de la Cruz». Carmen Beatriz López Portillo (ed.). Sor Juana y su mundo. Una mirada actual. México: Universidad del Claustro de Sor Juana-Fondo de Cultura Económica, 1998: 85-94.

BénAssy-Berling, Marie-Cécile. Humanismo y religión en Sor Juana Inés de la Cruz. México: UNAM, 1983.

Bouvier, Virginia M. «La construcción de poder en Neptuno alegórico y Ejercicios de la Encarnación». Sandra Lorenzano (ed.). Aproximaciones a Sor Juana. México: Universidad del Claustro de Sor Juana-Fondo de Cultura Económica, 2005: 43-54.

Català, Rafael Enrique. «El Neptuno alegórico de Sor Juana: ontogenia de América». Plural, 13.7, 151 (1984): 17-27.

Conti, Natale. Mythologiae sive explicationum fabularum libri decem. Coloniae Allobrogum: s.i., 1536. [Venecia: Aldo Manutio, 1551].

Cortijo Ocaña, Antonio. Sor Juana Inés de la Cruz o la buisqueda de identidad. Sevilla: Renacimiento, 2015.

Cortijo Ocaña, Antonio. «Estudio introductorio». Calderón de la Barca. El sacro Pernaso. Kassel: Reichenberger, 2006.

FARRÉ VIDAL, Judith. «Las loas de sor Juana, razones son finezas». Sara Poot Herrera y Antonio Cortijo Ocaña (eds.). Sor Juana Inés de la Cruz. La construcción de 
lo femenino en su obra menor. Los mundos cortesano y festivo de loas y villancicos. Número monográfico de Anthropos, 243 (2016): 49-68.

Fassina, Alessia. Una patrizia romana al servizio della fede: il centone cristiano di Faltonia Betitia Proba. Tesis doctoral inédita. Venezia: Università Ca’ Foscari, 2004.

Green, Roger. P. H. «Proba’s Cento: Its Date, Purpose and Reception». Classical Quarterly, 45 (1995): 551-563.

Green, Roger. P. H. «Proba's Introduction to her Cento». Classical Quarterly, 47 (1997): 548-559.

Grossi, Verónica. «Figuras políticas y epistemológicas en el Neptuno alegórico de Sor Juana Inés de la Cruz». Romance Quarterly, 51.3 (2004): 183-192.

Jáuregui, Carlos A. «Elplato más sabroso: eucaristía, plagio diabólico, y la traducción criolla del caníbal». Colonial Latin American Review, 12.2 (2003): 199-231.

Jáuregui, Carlos A. «Cannibalism, the Eucharist, and Criollo Subjects». Ralph Bauer y José A. Mazzotti (eds.). Creole Subjects in the Colonial Americas: Empires, Texts, Identities. Chapel Hill: Omohundro Institute of Early American History and Culture-The University of North Carolina Press, 2009: 61-100.

Juana Inés de la Cruz, Sor. Poesía, teatro, pensamiento. Lírica personal. Lírica coral. Teatro. Prosa. Georgina Sabat de Rivers y Elias Rivers (eds.). Madrid: Espasa, 2004.

Juana Inés de la Cruz, Sor. Obras completas. Eds. Alfonso Méndez Plancarte (vols. I-III) y Alberto G. Salceda (vol. IV). México: Fondo de Cultura Económica, 1951-1957.

Juana Inés de la Cruz, Sor. Neptuno alegórico. Ed. Vincent Martin. Introd. Electa Arenal. Madrid: Cátedra, 2009.

Kircheri, Athanassi. Prodomus Coptus Aegyptiacus. Roma: Typis Sacrae Congregationis de Propaganda Fide, 1656.

Kircheri, Athanassi. Obeliscus Pamphilius, hoc est Interpretatio nova \& hucusque intentata Obelisci Hieroglyphici. Romae: Typis Ludovici Grignani, 1650.

Kircheri, Athanassi. Oedipus Aegyptiacus. Roma: Typis Sacrae Congregationis de Propaganda Fide, 16521654. 3 vols.
Kircheri, Athanassi. Obelisci Aegyptiaci...interpretatio hieroglyphica. Romae: Ex Typographia Varesii, 1666.

KIRCherI, Athanassi. Principis Christiani archetypon politicum. Amstelodami: Apud Joannem Janssonium a Waesberge, 1772 [1669].

Martínez-San Miguel, Yolanda. Saberes americanos: subalternidad y epistemología en los escritos de Sor Juana. Pittsburg: Universidad de Pittsburgh-Instituto Internacional de Literatura Iberoamericana, 1999.

Moraña, Mabel. «Colonialismo y construcción de la nación criolla en Sor Juana Inés de la Cruz». Mabel Moraña. Viaje al silencio. Exploraciones del discurso barroco. México: UNAM, 1998: 199-215. [Accesible en: http://www.cervantesvirtual.com/obra-visor/viajeal-silencio-exploraciones-del-discurso-barroco--0/ html/e5b96feb-bf21-4bd2-be1c-9389af0cb0ba_52. html\#I_0_]

Olivares Zorrilla, Rocío. «Avances en la anotación del Primero sueño, de Sor Juana Inés de la Cruz». Etiópicas. Revista de Letras Renacentistas, 7 (2011): 64-86.

ReIluy, Conor. Athanasius Kircher: A Master of a Hundred Arts, 1602-1680. Wiesbaden: Edizioni del Mondo, 1974.

RivoseCCHI, Valerio. Esotismo in Roma Barocca: Studi sul Padre Kircher. Roma: Bulzoni, 1982.

Vitoria, Baltasar de. Primera parte del Teatro de los dioses de la gentilidad. Madrid: Imprenta Real, 1657. 3 vols.

VItORIA, Baltasar de. Teatro de los dioses de la gentilidad. Madrid: Juan de Aritzia, 1737. 3 vols.

Schnapp, Jeffrey. «Reading Lessons: Augustine, Proba, and the Christian detournement of Antiquity». Stanford Literature Review, 9.2 (1992): 99-123.

Zanelli, Carmela. "La loa de El divino Narciso de Sor Juana Inés de la Cruz y la doble recuperación de la cultura indígena mexicana». José Pascual Buxó y Arnulfo Herrera (eds.). Literatura novohispana. Revisión critica y propuestas metodológicas. México: UNAM, 1994: 183-200.

Zugasti, Miguel. La alegoría de América en el barroco hispánico: del arte efimero al teatro. Valencia: Pre-Textos, 2006. 